\title{
Population structure and speciation in the dragonfly Sympetrum striolatum/nigrescens (Odonata: Libellulidae): An analysis using AFLP markers
}

\author{
Katharine A. PARKES ${ }^{1}$, William AMOS $^{2}$, Norman W. MOORE 3 , Joseph I. HOFFMAN ${ }^{2 *}$ and JANet MOORE ${ }^{2}$ \\ ${ }^{1}$ British Dragonfly Society, c/o Natural England (West Midlands), Attingham Park, Shrewsbury, Shropshire, SY4 4TW, UK \\ ${ }^{2}$ Department of Zoology, University of Cambridge, Downing Street, Cambridge, CB2 3EJ, UK \\ ${ }^{3}$ Retired
}

Key words. Gene flow, STRUCTURE, morphotypes, dragonfly, Odonata, Sympetrum striolatum/nigrescens

\begin{abstract}
There has been a long-standing debate as to whether Sympetrum striolatum (Charpentier, 1840) and the darker northern form, S. nigrescens (Lucas, 1912) should be recognised as separate species of dragonfly. Here we address this question using genetic analysis based on AFLP markers and samples collected from sites across the species' United Kingdom range. The program STRUCTURE finds no support for specific status. Instead, it reveals strong patterns of divergence between populations sampled from Scottish islands and those on the mainland, suggesting that salt water is a major barrier to gene flow. Thus, the dark form is quite likely to reflect a beneficial polymorphism that allows individuals to take advantage of short periods of warmer weather. Our AFLP markers appear to be very rapidly evolving, showing little or no overlap between congeneric species, and hence are ideally suited to answering questions relating to the levels of gene flow among populations within species.
\end{abstract}

\section{INTRODUCTION}

Molecular genetic tools play an increasingly important role in ecology, helping to resolve questions across a wide range of scales, from assessment of paternity and social organisation, through analysis of population structure up to the determination of taxonomic relationships. Taxonomy in particular is experiencing a renaissance, with the advent of barcoding projects aiming to characterise large numbers of poorly studied species in terms of defined genetic traits. In many cases, molecular results have supported classical morphological work, but there are cases where unexpected novelty emerges. A recent example is provided by the whiskered bat where genetic studies uncovered two cryptic species with different calls (Von Helversen et al., 2001).

Flying insects provide some of the most challenging subjects for taxonomists. On the one hand, whether under their own volition or carried by wind, mixing between populations is possible over large geographic ranges. On the other hand, fine-scale local adaptation is likely, reflecting different food sources, predators, thermal regimes or other factors. One such long-standing issue (Hammond \& Merritt, 1985; Brooks, 2002) involves the classification of two species of dragonfly, Sympetrum striolatum (Charpentier, 1840) and Sympetrum nigrescens (Lucas, 1912). S. nigrescens differs mainly from $S$. striolatum in having more extensive dark markings on the thorax and abdomen, and continuation of the black line across the base of the frons a little way down beside the eyes (Hammond \& Merritt, 1985). However, in practise these features are not considered to be sufficiently com- pelling for confident separation in the field (Merritt et al. 1996).

The recorded distribution of Sympetrum striolatm / $S$. nigrescens in the British Isles shows a wide gap between records on the West coast of Scotland, including the Hebrides, and southern Scotland and England. During the period 1943-2008, one of us (NWM) visited the east of Scotland, mainly the Spey and Dee valleys, twelve times within the flying season of the species. Over this 55-year period neither $S$. striolatum nor $S$. nigrescens were observed, despite numerous Sympetrum danae being present, as in the west of Scotland.

During the period 1950-2005 sixteen visits were made to the West coast of Scotland and the Hebrides in the flying season and numerous $S$. nigrescens were observed, thus confirming the distribution shown in Merrit et al. (1996) and the gap between the two populations. Many individuals from the west coast of Scotland and the Inner and Outer Hebrides were closely examined, showing them all to be darker than equivalent specimens from England. In the few cases where secondary genitalia were examined, no consistent differences between the two forms were found, thus confirming Merritt \& Vick (1983). In addition, numerous observations were made on the behaviour of $S$. striolatum and $S$. nigrescens in the field. In West Scotland and the Hebrides, male insects were frequently holding territories perched on the ground in weather conditions under which English examples would generally be absent. This enabled them to use short spells of sun on grey windy days, which are frequent in West Scotland, and suggests a selective benefit for their darker colour.

\footnotetext{
* Corresponding author; e-mail: jih24@cam.ac.uk
} 
In a study of morphology by Gardner (1955), it was asserted that $S$. striolatum may occur in darker forms, and that there is a distinction in the hamuli of males and in the vulvar scale of females that can be used to separate $S$. nigrescens. However, a later repetition of this study found insufficient evidence to support the earlier claim, with the authors unable to ascribe specimens to either nigrescens or striolatum (Merritt \& Vick, 1983). More recently Pilgrim \& Von Dohlen addressed the problems of several species pairs of Sympetrum, including $S$. nigrescens and S. striolatum (Pilgrim \& Von Dohlen, 2007). Their study considered both morphological and genetic traits and proposed that $S$. nigrescens is not a valid species. Unfortunately, the study only used specimens of $S$. nigrescens from Norway, specimens described as $S$. nigrescens/striolatum intermediates from Ireland, and specimens of $S$. striolatum from Japan, the Netherlands and Turkey, and not in consistent numbers.

In order to understand more fully the genetic relationships between $S$. nigrescens and $S$. striolatum, the work undertaken here was designed specifically to examine these two species in their best described range. Fieldwork was undertaken to provide robustly comparable sets of specimens.

\section{METHODS}

\section{Sample collection}

Ten samples of $S$. striolatum were collected from each of three different populations in England; near Newcastle, the Norfolk Broads and Dungeness, Kent (Fig. 1). An additional 3 samples were also collected from London and four from Hertfordshire. Sets of ten S. nigrescens were collected from Scotland; on the mainland near Oban, on Colonsay and on South Uist. To allow genetic comparison across the genus and the family, a set of ten specimens of $S$. danae was collected from the Scottish mainland near Oban, and a set of ten specimens of Orthetrum cancellatum was collected from the Norfolk Broads. Fieldwork was completed in Scotland between the $14^{\text {th }}$ and the $23^{\text {rd }} \mathrm{July}$, in Norfolk between the $10^{\text {th }}$ and the $14^{\text {th }}$ August, in Northeast England on the $11^{\text {th }}$ and $12^{\text {th }}$ September and in Kent on the $18^{\text {th }}$ September, all during the 2007 flight season. Individuals were collected using a fine mesh net with no preference given to age or sex. Specimens were frozen using an alcohol based freeze spray and immediately dissected, the thorax only being preserved in $70 \%$ ethanol.

\section{Genetic analysis}

We chose to use amplified fragment length polymorphisms (AFLPs,Vos et al., 1995). Taxonomic studies often use maternally inherited mitochondrial DNA, but this marker may yield ambiguous results in a species where maternally directed site fidelity to the body of water in which a nymph develops, should it exist, could create strong population structure that belies male-mediated gene flow. In view of this, we decided that

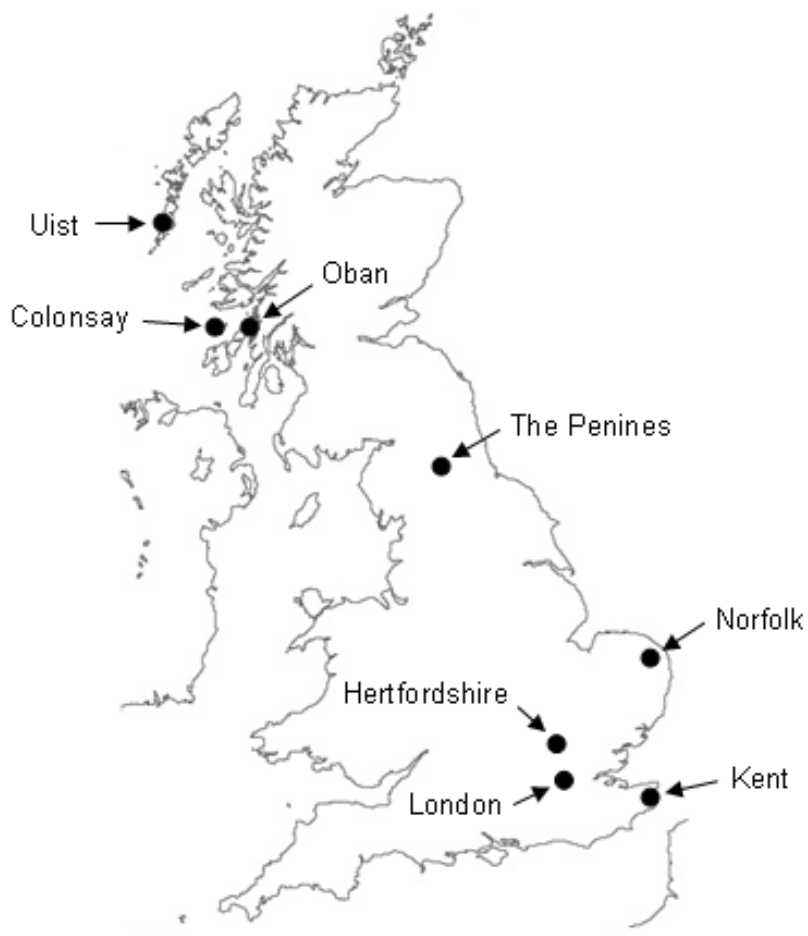

Fig. 1. Map of the United Kingdom showing sampling locations of $S$. striolatum and $S$. nigrescens.

nuclear markers would provide the best chance of resolving the current problem, and AFLPs offer the chance to collect data from large numbers of reliably scorable traits even in species where, for example, microsatellite markers have not been developed.

Total genomic DNA was first extracted using a standard phenol-chloroform protocol. The AFLP protocol was similar to that used by Vos et al. (1995) and is described in detail by Dasmahapatra et al. (2009). Briefly, 100-400 ng of genomic DNA was first digested using $\operatorname{Taq} \mathrm{I}\left(5 \mathrm{U}\right.$ in a $10 \mu \mathrm{l}$ volume at $65^{\circ} \mathrm{C}$ for $2 \mathrm{~h}$ ) and then with $E c o R I$ ( $5 \mathrm{U}$ in a $20 \mu 1$ volume at $37^{\circ} \mathrm{C}$ for 2 h). TaqI and EcoRI and adapters (Ajmone-Marsan et al., 1997) were then ligated onto the digested DNA using T4 DNA ligase ( $1 \mathrm{U}$ in a $50 \mu \mathrm{l}$ volume at $37^{\circ} \mathrm{C}$ for $3 \mathrm{~h}$ ), and the resulting products diluted by a factor of ten in $10 \mathrm{mM}$ Tris HCL and EDTA $(0.1 \mathrm{mM}, \mathrm{pH} 8.0)$. For the pre-amplification, $5 \mu 1$ of ligation mix was added to a $50 \mu \mathrm{l}$ PCRs containing Tris- $\mathrm{HCl}(10 \mathrm{mM}, \mathrm{pH}$ 8.3), $\mathrm{MgCl}_{2}(1.5 \mathrm{mM}), \mathrm{KCl}(50 \mathrm{mM})$, dNTPs $(0.2 \mathrm{mM})$, Taq polymerase $(1 \mathrm{U})$, and $50 \mathrm{ng}$ each of the TaqI-C and EcoRI-A pre-amplification primers (the primer sequences were 5'GATGAGTCCTGACCGAC-3' and 5'-GACTGCGTACCAA TTCA-3' respectively). Following 30 pre-amplification cycles $\left(30 \mathrm{~s}\right.$ at $94^{\circ} \mathrm{C}, 60 \mathrm{~s}$ at $50^{\circ} \mathrm{C}$, and $60 \mathrm{~s}$ at $72^{\circ} \mathrm{C}$ ) the products were diluted 10 times with $10 \mathrm{mM}$ Tris HCL and EDTA $(0.1 \mathrm{mM}, \mathrm{pH}$ 8.0). For the selective amplification, $2.5 \mu \mathrm{l}$ of the diluted preamplification product was added to a $12.5 \mu 1$ reaction containing Tris- $\mathrm{HCl}(10 \mathrm{mM}, \mathrm{pH} 8.3), \mathrm{MgCl}_{2}(1.5 \mathrm{mM}), \mathrm{KCl}(50 \mathrm{mM})$,

TABLE 1. Primer combinations used for the AFLP selective amplification and numbers of AFLP polymorphisms generated.

\begin{tabular}{lcc}
\hline TaqI primer (5'-3') & EcoRI primer (5'-3') & Number of polymorphic loci \\
\hline GATGAGTCCTGACCGA-CAG & GACTGCGTACCAATTC-ACA & 79 \\
GATGAGTCCTGACCGA-CCA & GACTGCGTACCAATTC-AGC & 32 \\
GATGAGTCCTGACCGA-CCA & GACTGCGTACCAATTC-ATG & 42 \\
\hline
\end{tabular}




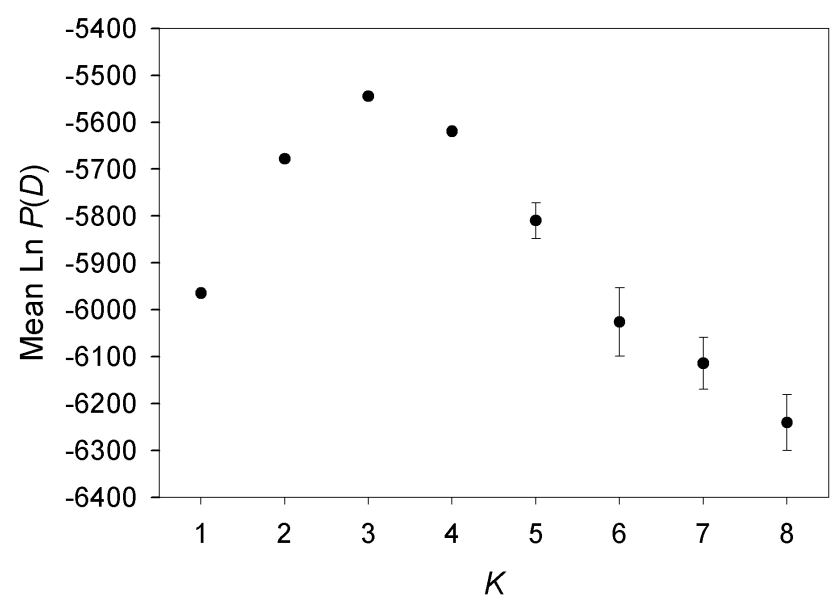

Fig. 2. Results of the STRUCTURE analysis showing mean \pm SE Ln $P(D)$ values based on five replicates for each value of $K$, the hypothesised number of groups represented in the data.

dATPs, dTTP and dGTP (0.2 mM each), dCTP (0.04 mM), $\alpha^{33} \mathrm{P}$-dCTP, Taq polymerase (0.2 U), TaqI selective primer (30 $\mathrm{ng}$ ), and EcoRI selective primer (5 ng). Samples were subjected to 13 selective amplification cycles $\left(30 \mathrm{~s}\right.$ at $94^{\circ} \mathrm{C}, 60 \mathrm{~s}$ at $65^{\circ} \mathrm{C}$, reducing by $0.7^{\circ} \mathrm{C}$ each cycle, and $60 \mathrm{~s}$ at $72^{\circ} \mathrm{C}$ ), followed by a further 23 cycles $\left(30 \mathrm{~s}\right.$ at $94^{\circ} \mathrm{C}, 60 \mathrm{~s}$ at $56^{\circ} \mathrm{C}$, and $60 \mathrm{~s}$ at $\left.72^{\circ} \mathrm{C}\right)$. Three different selective primer combinations were used to generate 153 polymorphic markers (Table 1). PCR products were resolved by electrophoresis on standard $6 \%$ polyacrylamide sequencing gels and detected by autoradiography. Exposed $\mathrm{X}$-ray films were assessed and if required, a second exposure was made for an adjusted time period.

\section{Band scoring and statistical analysis}

All bands in the approximate size range of 75-300 bp were scored manually by an experienced operator (WA). Only clearly polymorphic bands that could be scored in all individuals were included, these being recorded as $1=$ present and $0=$ absent.
Clearly non-independent pairs of bands were scored as single traits. Surprisingly, despite being close relatives, including one congeneric, our two control species, $S$. danae and $O$. cancellatum, showed essentially no band overlap with either $S$. striolatum or $S$. nigrescens. Those small numbers of bands that appeared to be of the same size numbered no more than expected by chance, and in no instance were convincingly homologous, always differing somewhat in appearance or intensity.

Once scored, banding patterns were analysed using the program STRUCTURE version 2.2.3 (Pritchard et al., 2000; Falush et al., 2003). STRUCTURE can handle data from various genetic markers, including unidominant AFLP bands, and uses a maximum likelihood approach to determine both the most likely number of distinct genetic groups in the sample $(K)$, and which individuals are most likely to belong to each group (the membership of each individual is estimated as $q$, which varies between 0 and 1 with the latter indicating full membership). This analysis is performed blind, without a priori knowledge of sampling location, and hence can be assessed for effectiveness by comparing group assignment with sampling location. We ran five independent runs for $K=1-8$ using $1 \times 10^{6}$ MCMC iterations after a burn-in of $1 \times 10^{5}$, specifying the correlated allele frequencies model and assuming admixture.

\section{RESULTS}

AFLP profiles exhibited large numbers of highly variable bands. Consequently, we needed to exploit only three different selective primer combinations (Table 1) in order to derive a total of 153 informative bands (control species excluded).

\section{STRUCTURE analysis}

The program STRUCTURE was run three times at each possible cluster size, from $K=1$ group, implying no population differentiation, through to $K=8$, which would imply every sample comes from a genetically different population. The replicate runs with each value of $K$ were highly concordant for their output log likelihood values.

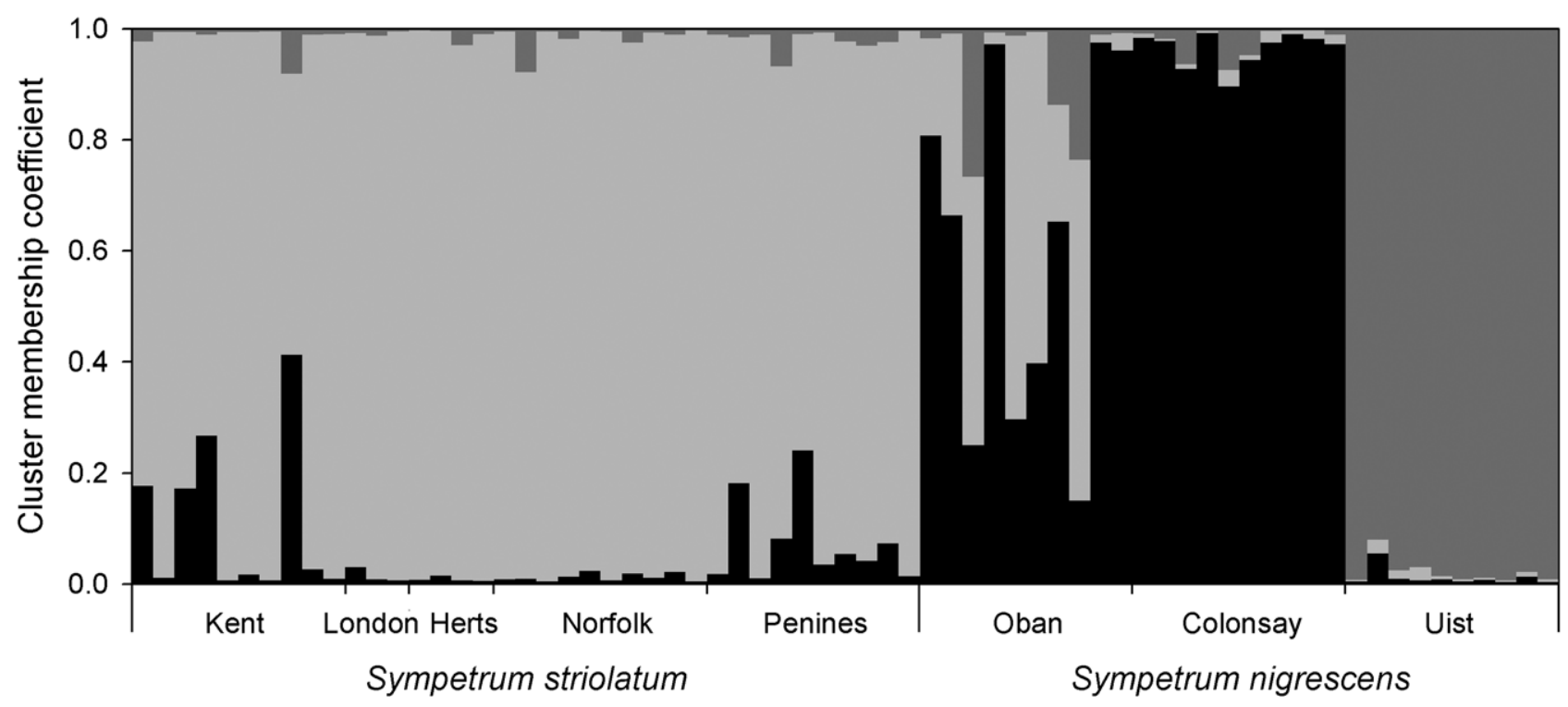

Fig. 3. Best clustering result ( $K=3$ clusters) using the program STRUCTURE (Pritchard et al., 2000). Each individual is represented by a vertical line partitioned into light grey, dark grey, and black segments, the lengths of which indicate the probability of membership in clusters $\mathrm{A}, \mathrm{B}$, and $\mathrm{C}$ respectively. 

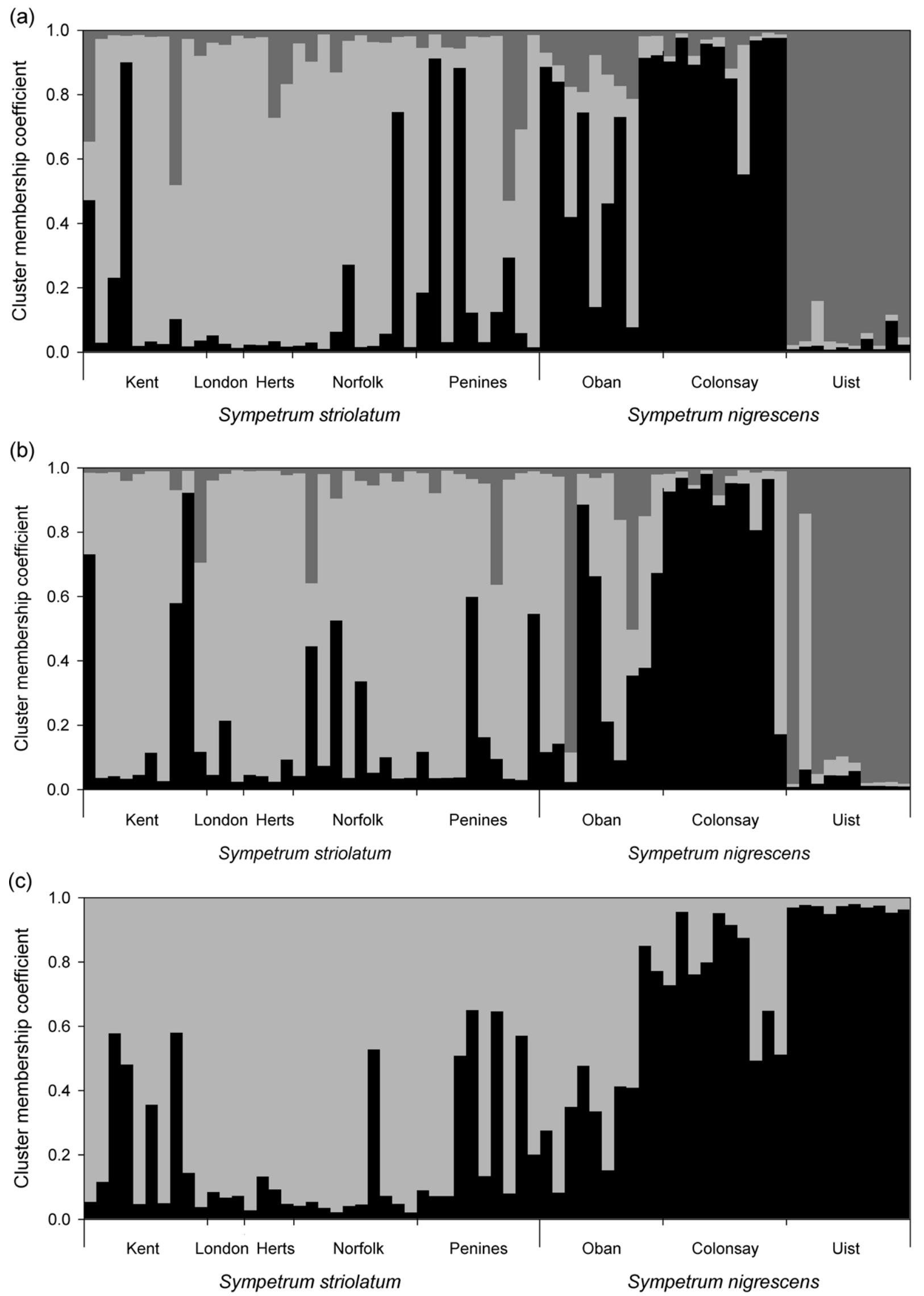

Fig. 4. Best clustering result obtained after restricting analyses to one selective primer combination: (a) TaqI-CAG and EcoRIACA; (b) TaqI-CCA and EcoRI-AGC; (c) TaqI-CCA and EcoRI-ATG. Each individual is again represented by a vertical line partitioned into different segments, the lengths of which indicate the probability of membership in different clusters. 
When STRUCTURE was run on the full dataset (control species excluded), the highest log likelihood value was associated with $K=3$ (Fig. 2), indicating three main population groups. Group membership for these inferred groups is summarised in Fig. 3, where each vertical bar represents a different individual, and the relative proportions of light grey, dark grey, and black indicating the relative probability of belonging to that group.

By inspection, the best defined group is the one associated with individuals from Uist (dark grey). Not only are all Uist samples assigned to this group with high confidence (each bar is almost entirely one colour), but this shade is also found little in any of the other samples. The two other groups, represented by light grey and black, also reveal strong group assignations in some, but not all samples. Black shading is overwhelmingly dominant among Colonsay samples, but occurs also in the Oban and, to a lesser extent, Kent and Pennine samples. Similarly, light shading is strongly characteristic of $S$. striolatum in general, but is also encountered in $S$. nigrescens from Oban and only reaches consistently high proportions in the Norfolk and London samples.

In addition to the analysis based on all scored bands together, we also tested whether each of the different primer combinations gave a similar signal, by repeating the analyses with each subset of bands separately (Fig. 4). Overall, there are no real surprises, the patterns reflecting what might be expected given a smaller sample of bands in each set, with lowered confidence on individual group membership and, in one case, a shift from three inferred groups down to two. Despite this, in no instance did we detect evidence of a clear partition into nigrescens and striolatum.

\section{DISCUSSION}

We have used AFLP markers to resolve the longstanding debate as to whether Sympetrum striolatum and $S$. nigrescens are sub-species or simply morphologically distinct variants of a single species. We find no evidence to support sub-specific classification, but instead uncover a clear pattern where isolated island populations sampled from the outer Hebrides exhibit genetic differentiation from their mainland counterparts.

The pattern of isolation and population groupings we find suggest strongly that the main barrier to gene flow in this genus is salt water. Thus, the most distinct grouping is formed by the Uist population from the outer Hebrides, which exhibits little affinity with any other sample site. Next most clearly defined is the sample from Colonsay, lying within 50 miles of Oban, a second sampling site that is separated by sea, not land. Colonsay individuals are uniformly and strongly assigned to this population. In contrast, Oban individuals show appreciable but highly variable affinity with Colonsay. Such a non-reciprocal situation suggests that while in good years Colonsay individuals may occasionally leave and find their way to the mainland, individuals in Oban probably prefer to disperse over land rather than sea, and so seldom or never make it out onto islands like Colonsay.
Our analysis provides no support for considering $S$. striolatum and $S$. nigrescens to be different species. This is consistent with previous studies by Merritt \& Vick (1983) and Pilgrim \& Von Dohlen (2007) that found no morphological or genetic differences between the two forms. Although we do reveal significant structuring across the UK, the major divisions between groups do not correspond to morphological classifications. In particular, samples from Oban appear highly mixed, containing individuals with affinities to both Colonsay and the southern samples. At the same time, although both Uist and Colonsay reveal almost complete separation from several southern England populations, these differences appear no greater than the difference seen between each other. An argument might be made that the striolatum populations are relatively homogeneous, but then these were all collected from contiguous mainland sites and even then display weak affinity with Colonsay in two cases.

Elsewhere Dasmahapatra et al. (2009) have shown that AFLPs can be useful for resolving species-level phylogenies. Therefore, we initially sought to use to related species as outgroups that would allow us to assess any differentiation that we found between $S$. striolatum and $S$. nigrescens. Unfortunately, the differences observed between $S$. danae and $O$. cancellatum, and also between both of these and $S$. striolatum and $S$. nigrescens, were so great that there was effectively no overlap. This precluded us constructing any kind of meaningful phylogeny. However, these large differences do suggest that valid species in this group are likely to exhibit substantially greater AFLP divergence than anything we see within our $S$. striolatum and $S$. nigrescens samples, where not a single band could be said to be diagnostic of a population, i.e. present in all individuals from that population but in no individuals from any other.

In conclusion, our genetic analysis lends strong support to the notion that $S$. striolatum and $S$. nigrescens represent morphs within a single species. Some reasonably strong population structure is detected across the British Isles, but this relates mostly to restricted gene flow associated with island populations, and not with the two morphotypes.

\section{REFERENCES}

Ajmone-Marsan P., Valentini A., Cassandro M., VecchiottiAntaldi G., Bertoni G. \& Kuiper M. 1997: AFLP markers for DNA fingerprinting in cattle. Anim. Genet. 28: 418-426.

Brooks S. 2002: Field Guide to the Dragonflies and Damselflies of Great Britain and Ireland. British Wildlife Publishing, Gillingham, $160 \mathrm{pp}$.

Dasmahapatra K.K., Hoffman J.I. \& Amos W. 2009: Pinniped phylogenetic relationships inferred using AFLP markers. Heredity. Doi: 10.1038/hdy.2009.25.

Falush D., Stephens M. \& Pritchard J.K. 2003: Inference of population structure using multilocus genotype data: linked loci and correlated allele frequencies. Genetics 164: $1567-1587$.

GARDNER A.E. 1955: A study of the genitalia of the two species Sympetrum nigrescens Lucas and S. nigrifemur (Selys) with notes on their distribution (Odonata: Libellulidae). Entomol. Gaz. 6: 86-108. 
Hammond C.O. \& Merritt R. 1985: The Dragonflies of Great Britain and Ireland. Harley Books, Colchester, 116 pp.

Merritt R. \& Vick G.S. 1983: Is Sympetrum nigrescens Lucas a good species? J. Brit. Dragonfly Soc. 1: 7-8.

Merritt R., Moore N.W. \& Eversham B.C. 1996: Atlas of Dragonflies of Britain and Ireland. The Stationery Office, Norwich, $151 \mathrm{pp}$.

Pilgrim E.M. \& Von Dohlen C.D. 2007: Molecular and morphological study of species-level questions within the dragonfly genus Sympetrum (Odonata: Lebellulidae). Ann. Entomol. Soc. Am. 100: 688-702.
Pritchard J.K., Stephens M. \& Donnelly P. 2000: Inference of population structure using multilocus genotype data. Genetics 155: 945-959.

Von Helversen O., Heller K.G., Mayer F., Nemeth A., Volleth M. \& Gombкото P. 2001: Cryptic mammalian species: a new species of whiskered bat (Myotis alcathoe n. sp.) in Europe. Naturwissenschassen 88: 217-223.

Vos P., Hogers R., Bleeker M., Reijans M., Vandelee T., Hornes M., Frijters A., Pot J., Peleman J., Kuiper M. \& ZabLEAU M. 1995: AFLP: a new technique for DNA fingerprinting. Nucl. Acids Res. 23: 4407-4414.

Received March 13, 2009; revised and accepted March 31, 2009 